\title{
Direct marketing in the UK: Trials and tribulations
}

Received (in revised form): 29th February, 2000

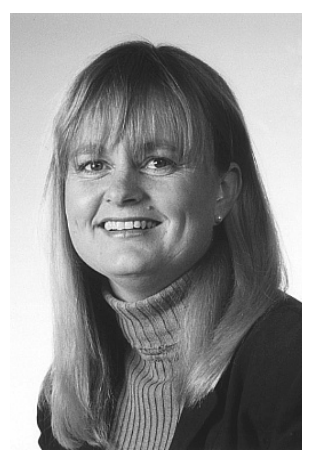

\section{Shena Mitchell}

is a Senior Lecturer in Marketing at The University of Portsmouth. She specialises in teaching Marketing Communications and Marketing Research at both undergraduate and postgraduate level. She is a research active member of staff, presently finishing her $\mathrm{PhD}$ and has published numerous papers in the area of direct marketing and consumer privacy. Shena also works as a marketing consultant for The University of Portsmouth Enterprise Limited and as an external examiner for the Chartered Institute of Marketing.

Abstract The purpose of this paper is to examine critically what constitutes direct marketing. The term direct marketing has variously been defined as a marketing strategy, a subset of relationship marketing, a communications technique and/or a distribution technique. It is not, therefore, surprising that these conflicting views have generated some confusion. The paper aims to examine the need for a definition, discuss some of the issues and terminology that create uncertainty, thus providing a framework that at least highlights, if not explains, some of the weaknesses identified within the literature.

\section{NEED FOR DEFINITION}

Academics agree that there is a need for a definition of direct marketing. ${ }^{1-6}$ Schultz states that 'to us, the definition of direct marketing is very important. It defines what we are and what we are doing. ${ }^{7}$ He continues:

'The definition of a field and discipline is important. If we are going to study direct marketing, we need to clearly define direct marketing... to the researcher, definitions are important. And they will likely become more important in the future'.

It would indeed be difficult to address various direct marketing issues such as trends, privacy, intrusion, data control, the environment and accuracy, without a precise definition of what direct marketing actually means. Schultz makes the following point:

'Let's start by defining what we mean by direct marketing and database marketing, relationship marketing and all the other terms and buzz words which are creeping into our vocabulary. If we don't I fear that what you are talking about when you say direct marketing may have absolutely no relationship to what I consider direct marketing. And for an academic discipline, that is the worst of all possible worlds.'

Bauer and Miglautsch also discuss the importance of a theoretical, conceptual or operational definition, stating that:

'There are several reasons why a direct marketing definition is important. First, the definition of a business area contributes to the professional image among the consumer and the business sectors. Second, the definition of a business area is used to delineate the area of academic purposes of research and teaching, diagnostic applied research purposes, and for identification and communication among the practitioners and consultant area' ${ }^{8}$

Bauer and Miglautsch also state that: 
'Only recently has the question of an accurate definition been broached, as a number of direct marketers have disagreed with each other over the years, without being sufficiently bothered by the disagreements to engage in a systematic discussion. Direct marketing as it exists in the world, so that any part, or subset, of it may be recognised for a "real" definition is the only one worth considering, as what is needed is a definition of what it is, so that readers may know what writers are referring to when they use the term'?

In agreement, Schofield concludes that:

'The problem is to know what one is talking about when discussing direct marketing, and, therefore, the need is for a real definition of the thing which direct marketing is, expressed in terms of other words whose meanings are clear and well known'. ${ }^{10}$

Many definitions provided by marketers are less definitive than they appear. That is not to say, however, that what constitutes direct marketing is not under debate; many have recently contributed to the discussion. ${ }^{11-13}$

\section{CONTRIBUTING FACTORS}

Schofield points out that 'all of the few direct marketing text books begin with the definition of direct marketing given by the DMA' (meaning the American Direct Marketing Association, ADMA). ${ }^{14}$ Schofield may be exaggerating slightly, not all textbooks use this definition, however, it may be fair to say that most do. Despite the unsuitability of an American direct marketing definition being adopted as a working definition for the UK, due to cultural differences. ${ }^{15}$ Therefore, a good starting point would be to review the definition used by the ADMA, as cited in Roberts and Berger:

'Direct marketing is an interactive system of marketing which uses one or more advertising media to effect a measurable response and/or transaction at any location'. ${ }^{16}$

Interestingly, Bauer and Miglautsch and O'Malley, Patterson and Evans discuss the ADMA definition and find the following faults:

— it focuses upon media

- direct marketing is categorised as a simple element of the communications mix

— it does not include elements of interaction at an individual level. Bauer and Miglautsch put forward 'relational marketing' as a more appropriate term than 'interaction'

- feedback from customers, which would facilitate dialogue, is not included

- it uses the specific term 'advertising', rather than a more general term such as 'marketing communications'

- it contains the phrase 'a measurable response and/or transaction'. All businesses measure response and this does not help to distinguish direct marketing from general marketing and advertising. It could, however, be solved by stating measurement at an individual level

- the use of 'location' is criticised because customers are not necessarily limited by location - they could respond by telephone, mail, fax, e-mail or personal visits, possibly at a kiosk.

The point made about 'all businesses measure response' is not necessarily accurate and, therefore, could be seen as a key term and criterion for a direct marketing definition. Indeed it is argued by some, such as Roberts and Berger ${ }^{17}$ that measurability is of paramount importance to a direct marketing definition. The points made by O'Malley, Patterson and Evans regarding 
interaction and feedback also need some consideration.

Some definitions and sub-definitions of direct marketing have been criticised if they exclude the terms 'interaction' or 'feedback', but it is difficult to see why this should be the case since direct marketing can exist without interaction and invariably does. Schofield continues this line of thought by stating that:

'Direct marketing with tracking codes (or lifetime value calculations, or the use of a database) would undoubtedly be more effective, but direct marketing without it would still be direct marketing. The concern of definers should be to define the reality of the subject or business as it really exists, not to 'define out' any direct marketing which is imperfect, or ineffective, or falls below the highest standards'. ${ }^{18}$

O'Malley, Patterson and Evans agree with Schofield that a definition should not 'define out', however, definitions will naturally define out, through the process of selecting which terms should be excluded or included in the definition.

The Institute of Direct Marketing (IDM) marketing diploma syllabus states that any direct marketing definition should contain the concepts of 'interaction', 'control', 'targeting' and continuity', and that when defining modern direct marketing as a cybernetic process - as they do - it should also contain sub-definitions such as 'direct response advertising', 'prospecting', 'conversion', 'maintenance', 'relationship marketing', 'cybernetics' and 'macro-control'. These sub-definitions appear to have been adapted from the earlier work of Bauer and Miglautsch who define direct marketing as:

'a relational marketing process of prospecting, conversion, and maintenance that involves information feedback and control at the individual level by using direct response advertising with tracking codes'. ${ }^{19}$

Based upon a critique of current definitions, Bauer and Miglautsch propose a definition that consists of the four properties:

— relational marketing

- process of prospecting, conversion and maintenance

— information feedback and control at the individual level

— direct response advertising with tracking codes.

A definition built upon 'sub-definitions' or 'properties' is possibly complete, but may be difficult to use. Bauer and Miglautsch's direct marketing definition does indeed receive much criticism $^{20,21}$ including that:

- it defines direct marketing as a concept rather than a field of study

- certain terms are ambiguous, eg 'relational', 'prospecting', 'conversion' and 'maintenance'

- it espouses an ideal type, rather than being based on reality

- elements of it exclude much marketing work which employs individual direct marketing techniques on a pragmatic and eclectic basis

- it includes too many elements and all of these together are not necessarily evident in the practice of direct marketing

- it is attempting to define what would be ideal or most effective direct marketing.

Some of these criticisms are valid, while others are not. For example, the first criticism of the definition is that it is conceptual but - surely the whole point of Bauer and Miglautsch's paper is to 


\begin{tabular}{|c|c|c|}
\hline & Relationship & Transaction \\
\hline Strategic & $\begin{array}{l}\text { Stone et al. (1995) } \\
\text { Mitchell (1998) } \\
\text { Tapp (1998) } \\
\text { Holder (1992) }\end{array}$ & \\
\hline Tactical & $\begin{array}{l}\text { Bird (1996) } \\
\text { Fill (1996) } \\
\text { Bauer and Miglautsch } \\
(1992)\end{array}$ & $\begin{array}{l}\text { Adcock et al. (1995) } \\
\text { Kotler et al, (1996) } \\
\text { Tempest (1995) } \\
\text { DMA (1995) } \\
\text { ADMA (1998) } \\
\text { Squires (1993) } \\
\text { Dibb (1994) }\end{array}$ \\
\hline
\end{tabular}

Figure 1 Direct Marketing ${ }^{43}$

provide a purely conceptual definition. This point should therefore be an observation rather than a criticism. A philosophical discussion of the paper in its entirety and the use of sub-definitions and properties, rather than criticism of the offered definition, would have been more beneficial.

\section{DEFINITION MAP}

In an attempt to replicate the IDM approach a selection of direct marketing definitions were listed in order to decipher sub-definitions and similar properties. (See Appendix 1, p. 26). Based upon these definitions, a map was designed with the intention of exploring the content of existing definitions in more detail, not only methodically comparing the content of each definition, but also the meaning. The map proves useful as a simple measure of the definitions in use, juxtaposing ideas and possible links between authors' writing styles. For example, definitions given by authors that have been placed within the 'strategic' school contain words such as 'approach', 'strategy', 'planning', 'targeted', 'measurable' and 'long term'.
Authors from the 'tactical' school use words such as 'media', 'communications', 'promotional tools' and 'quantifiable'. In addition to this, it appears that definers tend to focus more on either relationships or databases. For example, 'relationship' definitions include terms such as 'individual', 'direct contact', 'direct response', 'loyalty', 'mutual reward', 'relationship' and 'consumer', whereas 'database' definitions use the terms 'databases', 'systematic', 'information' and 'data collection' (see Figure 1).

Figure 1 is not intended to be accurate and it would be interesting to send the table to the 'definers' and ask them to place themselves within the grid. The exercise of identifying the diversity and prevalence of terms used, in order to understand the approaches used by different definers, proves useful in itself, however. The definition map also enables the identification of similarities between direct marketing definitions by linking terms such as 'strategic' and 'tactical' or 'transactional' and 'relational'. From this, the definitions are classified into categories in order to examine them further within their own quadrants. 
The first quadrant shows direct marketing systems, the second quadrant holds direct marketing techniques, the third quadrant is classified as direct selling with the aim of initiating a response and the fourth quadrant shows types of media and communications used in direct selling. It is important at this stage to review these schools of thought. The first being that direct marketing is a communications technique. This is especially common within marketing communication text books such as Fill. ${ }^{22}$ Tapp extends this observation and states that:

'Mainstream marketing texts, for example Dibb et al. (1994), Adcock et al. (1993), and Brassington and Petitt (1997) (and also marketing communications texts, eg Smith, 1993), tend to view direct marketing as confined to the marketing communications mix'. $^{23}$

Direct marketing is not a simple concept, and although confining direct marketing as a bolt on to the promotional mix may be tidy, it is impractical. Direct marketing cannot simply be another promotional tool, because it is a technique that may use one or more of a range of promotional tools. The distinguishing characteristics of the direct marketing technique are surely the directness of its strategic approach and dealings with individual responses. O'Malley, Patterson and Evans state that:

'Because of the variety of applications encompassed by direct marketing it is increasingly being employed by organisations who are not 'direct marketers' in the traditional sense. However it is also the range of application which makes developing a generic definition of direct marketing so difficult. Any definition is going to be problematic as it must incorporate both direct distribution and direct communications. A second problem is identifying what media and methods are appropriate in the definition'. ${ }^{24}$

Alistair Tempest, who is the managing director of European Direct Marketing Association (EDMA), states that direct marketing is:

'A marketing technique using a number of different media which involves direct contact between an organisation and an individual consumer or company, and seeking a measurable response'. ${ }^{25}$

The researcher suggests that important elements of this definition are that:

- direct marketing is described as a 'marketing technique' that is supported by different media

- direct marketing involves direct contact rather than response (which would be ideal, but not real in all cases)

- there is mention of individual contact, rather than consumers as groups

- a measurable response of some sort is sought, rather than quantifiable.

As with most direct marketing definitions, Tempest's definition is limited and misses out elements relating to distribution and marketing strategies. Stone, Davies and Bond offer a more comprehensive definition that incorporates most of the requisite terms as defined later in this paper:

'Direct marketing is the planned implementation, recording, analysis and tracking of customers' direct response behaviour over time in order to derive future marketing strategies for developing long-term customer loyalty and ensuring continued business growth'. ${ }^{26}$

The inclusion within the definition of planning, recording, tracking, customer behaviour, future strategies, developing 
long-term customer loyalty and continued business growth all indicate that Stone, Davies and Bond consider direct marketing to be a strategic approach, determined by the customer. Yet the overall meaning of the definition does appear to be at the end of the process in that it discusses what happens when there is a response, rather than how to get a response, which makes the assumption that the information comes first. Although likely, this is not always the case. The general theory is based upon the following points:

- direct marketing communications aim to initiate a response that is more than a purchase

- direct marketing communications aim to appeal to the individual customer rather than homogeneous groups of customers or the mass market.

In comparison, there is direct marketing as a 'channel of distribution', rather than a promotional tool, eliminating the middleman and the distributor from the marketing channel wherever possible. In particular, Davies ${ }^{27}$ and Dibb et al. ${ }^{28}$ define direct marketing as a 'distribution process'; other authors such as Tempest and Bird discuss direct marketing as a 'distribution process' but do not define it so. This point of distribution is discussed by Young who points out the following:

'Definition difficulties occur because direct marketing is neither a medium (like direct mail) nor a channel of distribution (like mail order); rather it is a means of communications which encompasses both media and channels and multimedia and multi-channels'. ${ }^{29}$

O'Malley, Patterson and Evans take the debate further by proposing that 'any direct marketing definition should incorporate both 'direct distribution' and 'direct communications'. ${ }^{30}$ They do not, however, continue with this discussion of distribution and communications, neither do they offer a definition that supports their claim that a direct marketing definition must incorporate both direct distribution and direct communications, offering instead two separate definitions. Many authors explore the possibility of two definitions. ${ }^{31-35}$

In the situation where two definitions are used, it may be more appropriate to have one definition for 'direct marketing techniques' and the other for 'direct marketing systems'. Schofield, as cited in O'Malley, Patterson and Evans, proposed that the first definition would be a general, inclusive definition of direct marketing, which would allow any use of any direct marketing technique to be recognised as an instance of direct marketing. The second definition would be of a direct marketing system, covering cases where a product or service is marketed exclusively by direct marketing methods.

For clarity and consistency it is important that reasonable assumptions be made about Schofield's discussion of the two definitions. The first assumption, concerning the first definition, is that when direct marketing is used 'at any time' - even in circumstances that may be driven by 'mass marketing', for instance - then if it uses 'direct techniques' they should be recognised as direct marketing for that instance. The next assumption is that the second definition is of a 'direct marketing system'; this could be interpreted to mean that all elements of the implementation stage are directed.

The underlying philosophy, aims and objectives of marketing a 'product or a service', either to 'mass or individual' markets, should be developed at a strategic level, whether the philosophy of the organisation is to be relational or transactional. Therefore, direct marketing 
should be defined as a strategic marketing 'system'. The system is then supported through directed communication and/or distribution techniques, which is identified as the 'process' of 'going to market'. As a solution to the problem of identification this is, however, still problematic. A solution is to use separate definitions for separate terms. For example, one definition for direct marketing and another for directed marketing communications, juxtaposed with definitions for marketing and definitions for marketing communications.

Few definitions, if any, however, actually define direct marketing purely as a strategic approach. If definitions indicate that direct marketing needs to be strategic, they also then include direct communications or direct distribution as an intrinsic tool. The point here is that if the definition emphasises strategy, then there is no need to include communications as all elements of the implementation stage, whether the marketing philosophy is relational or transactional, would be 'directed'.

Mitchell states that direct marketers may define marketing with a bias towards their profession, being subjective, with all the limitations that subjectivity brings. ${ }^{36}$ This point is also discussed by Bauer and Miglautsch, who state that 'the definer's own subjective view is also flawed by the influence of their working environment, tending to taint the definition'. ${ }^{37}$ Roberts and Berger state that:

'Both members of the public and people in the business community tend to have incorrect or incomplete ideas of what direct marketing is. They receive a great deal of unsolicited mail; they are annoyed by telephone calls from a computer; they see multitudes of consumer-good catalogues, only a few which contain merchandise that interests them' ${ }^{38}$
This is also probably true today and will affect any research that is conducted into direct marketing; therefore, understanding the problems is crucial to successful consumer research. Roberts and Berger state that lack of awareness about direct marketing can be attributed to four main issues:

- most prominent direct marketers have been entrepreneurs who have focused upon building the business, rather than building awareness of direct marketing

- few businesses or communications schools offer courses in direct marketing so few learn about the field or realise the career opportunities

- marketing professionals have regarded direct marketing as a faintly disreputable activity, full of hucksterism and outright deception

- direct marketing as a discipline has not been worthy of respect and thoughtful study. ${ }^{39}$

In addition to this it may be that direct marketing is not a stable and coherent entity - ie it is poorly defined by writers because it is poorly defined in reality.

\section{CONCLUSION}

Many of the issues surrounding the contributing factors could simply be explained by the fact that direct marketing is an ever changing business philosophy. As it changes and adapts to the need for better targeted marketing, and as the ability to target improves, the definition changes. One could add that direct marketing has a number of vestigial features, which are only triggered by environmental changes, such as 'technological developments'. But they are always there in content form... In fact, Tempest clearly identifies the 
difference in understanding and definition as a development, and suggests that direct marketing has evolved, become more sophisticated and can, therefore, be used by mass advertisers as well as direct. He states that:

'In the past it was usually in the form of a direct response mechanism - a coupon to be cut from a periodical or a newspaper or periodical, an address to write to, or a mail order catalogue with order forms, response envelope, etc. The techniques of direct marketing have slowly developed over time, with the introduction of mass marketing, and in doing so have collected a wide range of service industries specialising in the support systems needed - fulfilment houses which receive, process, package and post the product to the customer, letter shops, printers, list brokers, direct marketing agencies which provide the creative and strategic input, and a host of other services'. ${ }^{40}$

Tempest continues and confirms many of the arguments presented herein by stating that:

'Direct marketing is therefore not comfortable pigeon-holed as just another form of advertising, it is a mixture of advertising, retail distribution and sophisticated database management. It uses all forms of media, both mass and specialised (niche) media, and it relies on various carriers to provide the product to the customer at the end of the day (although the main carriers will continue to be - at least for the foreseeable future - the postal operators). Looked at in its entirety, therefore, direct marketing is a series of activities which are complex, and always developing as new computer systems are introduced'.

The Key Note report agrees with this train of thought and concludes that:

'As direct marketing has grown, the definition of what exactly direct marketing means has broadened enormously. Direct marketing used to be largely synonymous with direct mail, or what most people call "junk" mail. However direct marketing has also started to use press and television... this has blurred the distinction between direct marketing and conventional advertising. ${ }^{41}$

One solution to the problems faced in defining and understanding direct marketing is presented by Fletcher, Wheeler and Wright, who propose that direct marketing usage has gone through three phases, which are as follows:

- the 'sales orientated' phase in which direct marketing is seen as a channel of distribution to sell low-involvement, low-priced products very effectively

- the 'image building' phase in which direct marketing is, in a sense, 'a personalised image system'; the customer receives regular mailings targeted according to his or her life-style behaviour. A profile is thus built up and is used to motivate usage. Direct marketing, although still incomplete, is used as a medium

- the 'integrated system' phase in which the uses of direct marketing as a channel of distribution and as a medium come together to be used for both tactical and strategic purposes. In this stage direct marketing is integrated into the marketing process and database marketing ensures a long-term view of customer relationships. ${ }^{42}$

This is the most tangible solution in helping to understand the complexities of defining direct marketing; different approaches in 'going to market' have evolved and so have the definitions.

These phases suggested by Fletcher, Wheeler and Wright identify a development from the transactional Four Ps approach to a relational, relationship approach. This is a crucial issue, as 
phases in direct marketing could then be linked to changes in marketing from a transactional phase, using communications and distribution from the marketing mix, to a relational phase where relationship marketing has evolved as a separate type of marketing strategy to direct marketing. The development of these phases is known as either the 'paradigm' or 'relational' shift. As should now be clear there is a need for a clear and comprehensible definition of direct marketing that is theoretical, operational and conceptual. The following definition is offered, if only to encourage critical thinking about what direct marketing is, and it intends to be, in part, a contribution to existing knowledge:

'Direct marketing, as a marketing strategy, is a system that aims to target precisely defined markets. The marketing system incorporates various techniques, which are developed for the purpose of initiating a direct positive response between buyer and seller'.

There are a number of important points to make concerning this definition:

— first, the word 'strategy' is unequivocal, in that direct marketing is not merely a marketing communications technique. Direct marketing has indeed progressed to a marketing system which focuses upon precisely defined markets segmented by demographics, geographics, lifestyle, usage, behaviour and attitudinal variables

— the 'various techniques' are the way in which the marketing mix operationalises the strategy

- the aim of gaining a positive response means anything tangible or intangible. The response could be a number of things and is intended to be more than a purchase. For example, the customer may feel better about the organisation and tell others because the organisation was transparent in its approach, and treated the customer with respect. The response could merely be a one-off purchase, or the customer could send back information about themselves so that the organisation could understand them and target better in the future

- the desired response is not in all cases a relationship or consumer loyalty - the process of direct marketing does not always involve a sophisticated database - the small corner shop may also practice direct marketing.

The aim of this paper has not only been to review what direct marketing is, but also to understand why direct marketing is a complex and misunderstood term. Having taken into account a wide range of issues, a direct marketing definition has been offered for consideration and deliberation. The benefits of this definition are that it is a development of all previous definitions and has taken into account all the weaknesses and strengths surrounding those definitions.

The paper began by assessing some of the trials and tribulations associated with defining what direct marketing actually is. The need for a definition was reviewed, outlining the aims and the reasons for the paper. Some authors had previously identified what a direct marketing definition should contain and this was taken into consideration in the early stages of writing the paper to help in providing some thoughtful discussion.

\section{References}

1 Schultz, D. (1995) 'From the editor: What is Direct Marketing', Journal of Direct Marketing, Vol. 9, No. 2, pp. 5-9.

2 Tempest, A. (1996) 'Direct marketing and its future', in unpublished occasional paper, FEDIM.

3 Tapp, A. (1998) 'Principles of direct marketing', Pitman Publishing, Financial Times, London.

4 Bauer, C. L. and Miglautsch, J. (1992) 'A conceptual definition of direct marketing', Journal of Direct Marketing, Vol. 6, No. 2, Spring, pp. 7-17. 
5 O'Malley, L., Patterson, M. and Evans, M. (1998) 'Exploring direct marketing', Thomson International Press, London.

6 Schofield, A. (1995) 'The definition of direct marketing: A rejoinder to Bauer and Miglautsch', Journal of Direct Marketing, Vol. 9, No. 2, pp. 32-38.

7 Schultz (1995) op. cit., p. 5.

8 Bauer and Miglautsch (1992) op. cit. p. 8.

9 ibid, p. 10

10 Schofield (1995) op. cit., p. 35.

11 O'Malley, Patterson and Evans (1998) op. cit.

12 Tapp (1998) op. cit., p. 7

13 McDonald, W. J. (1995) 'Home shopping channel customer segments: A cross-cultural perspective', Journal of Direct Marketing, Vol. 9, No. 4, pp. 56-67.

14 Schofield (1995) op. cit., p. 6.

15 Mai, L. (1996) 'Direct marketing: An analysis of consumer characteristics and their perceptions of and attitudes to mail order speciality foods in the UK', PhD, University of Newcastle.

16 Roberts, M. and Berger, P. (1989) 'Direct marketing management', Prentice Hall,

Englewood Cliffs, New York, p. 2.

17 ibid.

18 Schofield (1995) op. cit., p. 8.

19 Bauer and Miglautsch (1992) op. cit., p. 10

20 Schofield (1995) op. cit., p. 35

21 O'Malley, Patterson and Evans (1998) op. cit.

22 Fill, C. (1999) 'Marketing communications frameworks, theories and applications', Prentice Hall, Hemel Hempstead.

23 Tapp (1998) op. cit., p. 14.
24 O’Malley, Patterson and Evans (1998) op. cit., p. 8.

25 Tempest (1996) op. cit., p. 17.

26 Stone, M., Davies, D. and Bond, A. (1995)

'Direct hit', Pitman Publishers, Boulton, p. 32.

27 Davies, M. (1998) 'Understanding marketing', Prentice Hall, Hertfordshire.

28 Dibb, S., Simkin, L., Pride, W. M. and Ferrell, O. C. (1994) 'Marketing: Concepts and strategies', Houghton Mifflin Company, Boston, 2nd European Ed.

29 Young, M. (1993) 'A practical man's guide to direct marketing', ADMAP, Vol. 28, No. 7, p. 25.

30 O'Malley, Patterson and Evans (1998) op. cit., p. 8.

31 Schofield (1995) op. cit.

32 Schultz (1995) op. cit.

33 Tempest (1996) op. cit.

34 Hart, N. A. (1996) 'The CIM marketing dictionary'. Butterworth and Heinemann, Oxford.

35 Fletcher, K., Wheeler, C. and Wright, J. (1991) 'Database marketing: A channel, a medium or a strategic approach?', International Journal of Advertising, Vol. 10, pp. 117-127.

36 Mitchell, S. M. (1997) 'Consumer attitudes towards direct marketing in the UK', Application to transfer from MPhil to $\mathrm{PhD}$, University of Portsmouth

37 Bauer and Miglautsch (1992) op. cit., p. 11.

38 Roberts and Berger (1989) op. cit., p. 2.

39 ibid.

40 Tempest (1996) op. cit., p. 3

41 Key Note (1997) 'Direct Marketing in the UK', Hampton, p. 48.

\section{APPENDIX 1}

Definition map

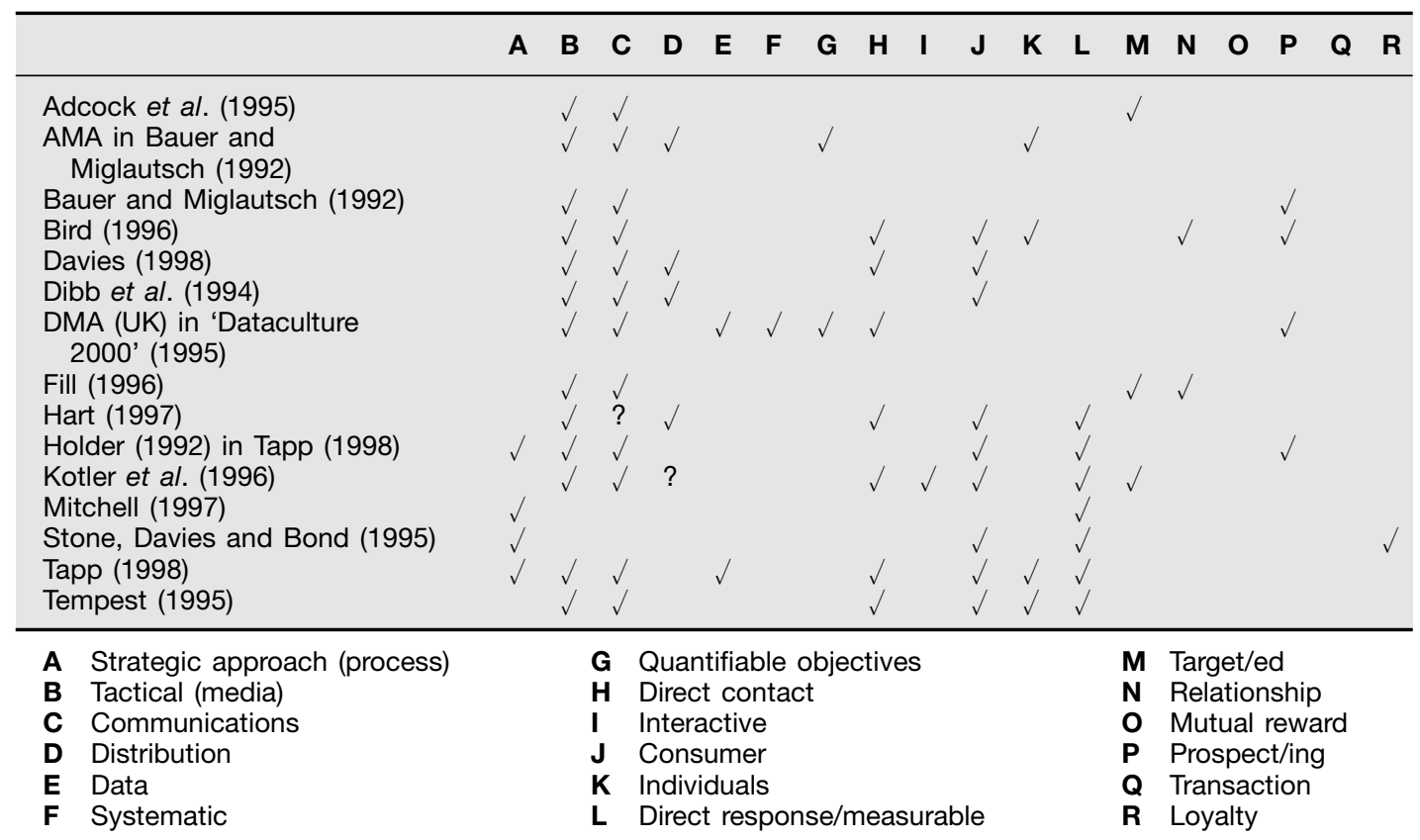


42 Fletcher, Wheeler and Wright (1991) op. cit., p. 48.

43 Stone et al. (1995). Mitchell (1997). Tapp (1998). Holder (1992). Bird (1996). Fill (1996) Bauer and Miglautsch (1992). Kotler et al. (1996). Tempest (1995). DMA (1995). ADMA (1998). Squires, S. (1993) 'The geography of direct marketing: Getting better answers to who and how and what in terms of where' Admap, July-August, pp. $40-41$

\section{Definition List: Theoretical, conceptual and operational}

Adcock et al. (1995, p. 255)

Direct marketing is the use of direct media to reach a target.

American Marketing Association in Bauer and Miglautsch (1992, p. 10), see Reference 4

$\ldots$ is the process of planning and executing the conception, pricing, promotion, and distribution of ideas, goods, and services to create exchanges that satisfy individual and organizational objectives.

Bauer and Miglautsch (1992, p. 10), see Reference 4

Direct marketing is a relational marketing process of prospecting, conversion, and maintenance that involves information feedback and control at the individual level by using direct response advertising with tracking codes.

Bird (1996, p. 30)

Direct marketing is: 'any advertising activity which creates and exploits a direct relationship between you and your prospect or customer as an individual'.

Davies (1998, p. 211), see Reference 27

Direct marketing is the non-personal communication and distribution by producers or suppliers direct to their consumers.

Dibb et al. (1994, p. 330), see Reference 28 Direct marketing: the use of non-personal media or telesales to introduce products to consumers, who then purchase the products by mail or telephone. DMA (UK) in 'Dataculture 2000' (1995, p. 9)

Communications where data is used systematically to achieve quantifiable marketing objectives, where direct contact is invited or made between company and its customers (and prospective customers). Fill (1996, p. 331)

Direct marketing is any measurable, media-based activity that seeks to create and sustain a mutually rewarding and personal relationship between two parties.

Hart (1996, p. 92)

Producer supplying direct to consumer without the use of any retail outlets. Includes mail order companies and direct response forms selling through the media or by post.

Holder (1992) in Tapp (1998, p. 9), see Reference 3

Direct marketing is the planned recording, analysis and tracking of consumer and business direct response behaviour to develop marketing strategies for current and future customers.

Kotler et al. (1996, p. 877)

Direct marketing uses various media to interact directly with carefully targeted consumers, generally calling for the consumer to make a direct response... Direct advertising vehicles are used to obtain immediate orders directly from targeted consumers.

Mitchell (1997, p. 67), see Reference 36 Direct marketing is a continuous strategic approach to marketing that with the aid of an integrated marketing mix, may initiate a direct response between the organisation and stakeholders, of positive value, that is measurable, controllable, timely and appropriate for the recipient and the continuing success of the organisation.

Stone, Davies and Bond $(1995$, p. 3), see Reference 26

Direct marketing is the planned implementation, recording, analysis and tracking of customers' direct response behaviour over time in order to derive future marketing strategy for developing long-term customer loyalty and ensuring continued business growth.

Tapp (1998, p. 10), see Reference 3

Direct marketing is a way of acquiring and keeping customers by providing a framework for three activities: analysis of individual customer information, strategy formation, and implementation such that customers respond directly.

Tempest (1996, p. 8)

A marketing technique using a number of different media which involves direct contact between an organisation and an individual consumer or company, and seeking a measurable response. 